\title{
Veteran teachers' identity: what does the research literature tell us?
}

\author{
Carmen Carrillo ${ }^{a}$ iD and Maria Assunção Flores ${ }^{b}$ (D)

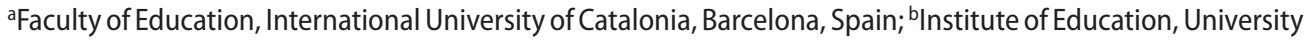 \\ of Minho, Braga, Portugal
}

\begin{abstract}
This paper provides an overview of research on veteran teachers and teacher identity. It analyses issues at the personal, situated and professional levels that have been shown to impact on veteran teachers' identities. The search included empirical studies published in peer-reviewed journals between 2005 and 2016. In total, 19 papers were analysed. Findings revealed that many studies focused on veteran teachers' resilience. Issues concerning veteran teachers' identities are key to understanding why they remain in the profession and are able to sustain their motivation and commitment over time. Many veteran teachers portrayed in the literature built on their confidence regarding their professional competence and relied on internal and external issues to maintain their motivation and commitment to teaching. The role of emotions in the transformation of veteran teachers identities and the permeable boundaries of the personal, situated and professional scenarios influencing veteran teachers'identities are highlighted in the paper.
\end{abstract}

\section{ARTICLE HISTORY}

Received 12 April 2017

Accepted 12 October 2017

\section{KEYWORDS}

Veteran teacher; professional identity; resilience; teacher commitment; teacher emotion

\section{Introduction}

Research on teacher identity is of vital importance to learn about and understand the issues that influence the motivation, job satisfaction and self-efficacy with which teachers exercise their profession (Day, 2002). The growing literature on teacher identity has mainly focused on finding out how teachers develop their identity in their transition from university to school and during their first years in the profession (Antonek, McCormick, \& Donato, 1997; Conway, 2001; Hong, 2010; Knowles, 1992; Pillen, Den Brok, \& Beijaard, 2013; Roberts, 2000; Sugrue, 1997; Volkmann \& Anderson, 1998). Less attention has been paid to how veteran teachers deal with the professional, situational and personal issues that can, at times, challenge their identity and the motivation and commitment with which they pursue their teaching careers. However, the study of veteran teachers' identity may provide very valuable information on the reasons why some teachers persist in the profession and why, with the passing of time, some of them are still committed to their work and find a sense of purpose and fulfilment in it. In a period of growing concern in many

CONTACT Carmen Carrillo ccarrillo@uic.es 
western countries due to teachers' shortage and their ageing (Organization for Economic Cooperation \& Development [OECD], 2005), and, at the same time, increasing measures of accountability strongly impacting the teaching profession, research on this topic may generate knowledge contributing not only to preventing veteran teachers from leaving the profession before retirement age, but also to understanding the issues that have an influence on teacher motivation and commitment (Gu \& Day, 2007). In addition to contributing to the decrease in teacher attrition rates, this study aims to generate knowledge to ensure that those who remain in the profession do not just survive, but are able to 'thrive professionally' (Beltman, Mansfield, \& Price, 2011, p. 186).

When it comes to conceptualising the term veteran teacher (VT), issues such as length of service, degree of expertise and commitment shown in the development of professional responsibilities are key elements. Although the literature agrees that the VT is one who has been teaching in the school for a long period of time, there exists a disparity of criteria in the length of service for a teacher to qualify as a 'veteran', perhaps as a result of the use of similar terms such as experienced or long-service in an indistinctive way. Unlike experienced or long-service, VTs are those who find themselves in the last phase(s) of their career, even close to their retirement age and, therefore, those who have served the profession for a minimum of 20 years (Bennett, Brown, Kirby-Smith, \& Severson, 2013; McIntyre, 2010; Meister \& Ahrens, 2011; Orlando, 2014). Other studies highlight professional dispositions and identify these teachers as 'accomplished', thus making reference to their ability to reflect on the experience and complexity of the teaching work (Lieberman \& Pointer Mace, 2009), or their degree of expertise in having spent many years developing their subject matter, pedagogical and didactic knowledge (Beijaard, Verloop, \& Vermunt, 1999). Although years of experience may be key elements to developing the abilities typical of an expert teacher, not all VTs may have achieved this status (Day \& Gu, 2009; Eilam, 2009; Margolis, 2008). In other words, more is needed than just years of experience in the teaching profession to become an expert or 'accomplished' teacher.

A look at the international research literature shows that some studies on VTs portray them as disengaged (Huberman, 1993), with diminishing levels of satisfaction (Van Houtte, 2006), commitment and enthusiasm (Goodson, Moore, \& Hargreaves, 2006) over time. Other studies, however, describe VTs as those who, despite difficulties in their immediate surroundings, continue to be committed and motivated in their profession (Cohen, 2009; Day \& Gu, 2009; Thorburn, 2014). In the VITAE project (Variations in Teachers' Work, Lives and Effectiveness), for instance, Day and colleagues (Day \& Gu, 2009; Day, Stobart, et al., 2006) found that in their late phases of teaching, there is an important number of teachers who continue showing a high level of motivation and commitment towards the work they do in spite of the hurdles associated with the excessive paperwork and heavy workload. In this study the term 'veteran teacher' is used to describe a teacher who has served the profession for a long period of time in the school setting (a minimum of 20 years) and who usually maintains a high degree of motivation and commitment towards the profession.

Existing literature on teacher identity has shown that it is not a stable entity, but a concept teachers use to explain and make sense of themselves in relation to the people and contexts in which they develop (Flores \& Day, 2006; MacLure, 1993). Identity (trans)formation is, thus, influenced by both the teacher's personal characteristics and previous experiences, thoughts and values, among others; and the teacher's attitudes, knowledge and abilities, his/her professional contexts and the people with whom he/she interacts in such contexts 
(Beauchamp \& Thomas, 2009; Beijaard, Meijer, \& Verloop, 2004; Day, Kington, Stobart, \& Sammons, 2006; Flores \& Day, 2006).

Teacher identity is, then, what one is or thinks he/she is, based on the meanings people attribute to themselves, and also on the perceptions other people have about them (Beijaard et al., 2004). These are subject to change as a consequence of the influences from the 'outside' or from the 'inside' (Pillen et al., 2013). These influences, which may have an impact on the personal, professional and/or situated level (Day, Stobart, et al., 2006), challenge teacher identity and teachers' capacity to sustain motivation and commitment. The fluctuations in these scenarios (e.g. the pressures and tensions as well as the supports received at these three levels) affect the relative stability/instability of their identities and therefore their willingness to remain in the profession or even their capacity to give the best of themselves in their classrooms as their level of commitment diminishes (Day, Kington, et al., 2006; Gu \& Day, 2007).

Due to the complex nature of teacher identity, research on this topic has been approached through a range of qualitative and quantitative methodologies, particularly from the perspective of pre-service and beginning teachers. In the case of VTs, the study of their identity is an area of research that has received little attention, partly due to the ambiguity around the term VT and therefore the lack of a clear delimitation and awareness of the challenges affecting their identity. As an underexplored area of research, there are limited studies specifically examining VTs' identity. This paper aims to address this gap in the literature by bringing together and synthesising current research that connects identity and VTs, delving into the issues and challenges influencing the transformation of VTs' identity and, through this, stimulating future debate regarding how to improve the quality with which VTs serve their profession. This study, which complements current research on VTs' identity and related constructs, has implications for teacher professional development and policy, school leadership and VTs themselves. It seeks to address the following research questions:

What is the focus of the studies that connect the theme of identity and VTs?

What kinds of research methods have been used to examine issues relating to VTs and teacher identity?

What aspects that have an impact on the identity of VTs influence the motivation and commitment with which they practise their profession?

What questions need to be examined in further research?

In order to respond to these questions, a selection of studies which relate both concepts VTs and teacher identity - has been reviewed and analysed. The results are presented in this paper, first from a descriptive perspective and then taking the personal, situated and professional scenarios influencing teacher identity as an analytical tool (Day \& Gu, 2009; Gu \& Day, 2007).

\section{Methods}

The search focused on the literature which, between January 2005 and May 2016, related the term 'veteran teachers' to the term 'professional identity'. The search was limited to this period after reading the literature review on teacher identity by Beijaard et al. (2004), in which these authors identify this topic as an 'emerging research area' (p. 125). It was also 
confirmed that an important part of the papers focused on the identity of the beginning teacher or the student teacher, so it was considered convenient to learn what had been done since then in relation to the identity of the VT.

During the first stage of the study, a search in the databases ERIC and Web of Science was performed. Publications whose title contained the term 'veteran teachers' (or the terms 'experienced teachers' or 'long-serving teachers', when these met the criteria regarding the length of service to be considered as a 'veteran') and which responded to the descriptor 'professional identity' were sought. A total of eight studies fulfilled the criteria established for this research in terms of the publication source (academic journals), the nature of the studies (empirical), the relevance of the topic (relating in a direct or implicit way VTs and teacher identity) and the nature of the sample (teacher sample with equal to or greater than 20 years' experience). Given that very few papers focused solely on teachers with this degree of experience, the final selection criterion in relation to this issue was that half of the sample or participants included in each paper met this standard so that the findings capture the particularities of VTs and are relevant to them. Although this study also aimed to focus on a sample of VTs who had remained committed to their profession over time in order to ensure that the findings provide relevant insights into how motivation and commitment can be sustained in the last years of the teaching career, this criterion was not finally adopted due to the limited number of papers providing this information.

During a later stage of the study, a manual search through the bibliography of some key papers was performed (Bryman, 2012). Papers that related 'veteran teachers' and other similar terms to the concept of 'teacher identity' and that fulfilled the four above-mentioned selection criteria were sought. This process generated a total of 11 papers that had not been found in previous searches.

The total of papers selected $(n=19)$ was subject to two types of analysis. The first analysis, descriptive in nature, incorporated the elaboration of a summary table for each of the papers that specified the focus of the study, the characteristics of the sample, the methods and their main findings (see Appendix 1).

Second, a content analysis (Ryan \& Bernard, 2000) of the findings of each paper was performed, which led to sorting the material into categories. This entailed the elaboration of a table that included, for each of the papers, extracts of the findings in relation to the categories ascertained for this study. These were based on the categories provided in the VITAE research project in regard to the scenarios in which teachers live and work (Day $\& \mathrm{Gu}, 2009 ; \mathrm{Gu} \&$ Day, 2007). Such scenarios are associated with the nature of the issues influencing teacher identity: (a) personal, related to their lives beyond school, which in this study also included personal traits and dispositions of the teacher as a person; (b) situated, related to their lives within the school, which includes their relationship with members of the educational community and the context to which the latter belongs; and (c) professional, referring to their values and beliefs, as well as to their interaction with outside political agendas and other elements of a professional nature. Therefore, these scenarios include factors (e.g. professional development opportunities), dimensions (e.g. teacher as a person) or even contexts ${ }^{1}$ (e.g. school context) of a personal, situated or professional nature but likely to have an influence at any of these levels.

Subsequently, a cross-analysis of the data was carried out, which entailed gathering the extracts in relation to each category across the selected papers. This allowed the finding of patterns among the various studies and contributed with data that make sense beyond 
every specific case (Huberman \& Miles, 1994), without disregarding the particular features of each paper.

In order to confirm the accuracy of the research process, two 'verification' strategies (Creswell, 1997) were implemented. Peer reviews conducted through regular meetings with a researcher not directly involved in the data collection and analysis provided an external check of the research process (Lincoln \& Guba, 1985). Prior to each meeting, the first author sent the work in progress to this researcher (second author) so that the latter had time to thoroughly review the material before each session. Then, during their meetings, the two researchers discussed and reflected together on both methodological and content issues arising throughout the research process: from the selection of the databases or the criteria established for the search, to the kinds of analysis conducted or other, more specific, details about how the analysis was being carried out. Written accounts of these sessions were kept to provide a data trail. This external and regular check provided insights that allowed us to refine the research process. In addition, thick descriptions for each of the selected papers were constructed. This included describing in detail the focus of each study, the characteristics of the sample, the methods and the most relevant findings (see Appendix 1) to allow readers to make decisions related to transferability of the findings (Erlandson, Harris, Skipper, \& Allen, 1993; Lincoln \& Guba, 1985) (see Appendix 1).

The results of both analyses are presented below: the first provides an overview of the selected research literature on VTs' identity and the second describes the issues in terms of the three categories (personal, situated and professional) that exert an impact on their identity and may influence the motivation and commitment with which VTs serve their profession.

\section{Results}

\section{Overview of the selected literature}

In order to provide a global view on the nature of the papers examined, this section discusses the most relevant results in terms of focus, methods and characteristics of the sample.

It was first confirmed that, although the purpose of this study is analysing what has been investigated on the identity of VTs, only two of the papers selected directly explored this matter (McIntyre, 2010; Thorburn, 2014), and the other 17 examined other aspects which either have an implicit connection with it or focus on similar topics through which it was believed it was possible to delve into the study of identity. An important number of these studies focused on matters such as teacher resilience and retention (Bennett et al., 2013; Brunetti, 2006; Cohen, 2009; Day \& Gu, 2009; Gu \& Day, 2007; Meister \& Ahrens, 2011) or the influence that specific programmes for professional development (or other types of programmes or activities allowing for the professional growth of the teacher) exert on the thinking or professional practice of these teachers (Deglau \& O'Sullivan, 2006; Flint, Zisook, \& Fisher, 2011; Levine, 2011; Ponte \& Twomey, 2014). Other papers dealt with aspects related to job satisfaction (Van Maele \& Van Houtte, 2012; Veldman, van Tartwijk, Brekelmans, \& Wubbels, 2013), teachers' beliefs or perceptions of teaching (Alger, 2009; Eilam, 2009), technology practices of VTs (Orlando, 2014), teacher-student relationships (Claessens et al., 2016) and the qualities of VTs (Santoro, Pietsch, \& Borg, 2012). 
In terms of methodological issues, almost half of the studies examined used qualitative methods $(n=9)$ with samples ranging between one and 20 participants. In eight studies, mixed methods were used, with samples that ranged between three and 74 teachers. Only two of the studies examined used quantitative methods, with samples ranging between 110 and 2091 participants, respectively. The main data source of the papers examined was interviews $(n=16)$, although most of them used additional data sources, questionnaires/surveys ( $n=5)$, observations $(n=5)$ or documents $(n=4)$ being three of the most frequently used. In regard to the nature of the sample, 13 of the 19 papers focused on experienced teachers, five on teachers with different levels of experience and one on pre-service teachers. This last one, however, examined the perceptions of such teachers concerning the qualities of a sample of VTs whom they had interviewed in a previous stage of the study.

\section{Considering the scenarios of veteran teachers' identity}

\section{The personal scenario}

There are different aspects related to the teacher's personal dimension, in reference both to the teacher's own dispositions or traits and to other internal and external issues, which are essential to understand why some VTs persist in the profession and find a high sense of purpose in it. The inner motivation to teach, which was reflected in some studies by expressions such as a sense of vocation, a passion for the profession or teaching as a calling was one of the most recurrent factors (Bennett et al., 2013; Day \& Gu, 2009; Gu \& Day, 2007; Santoro et al., 2012). In general, the literature describes these teachers as professionals who manage to keep a high level of motivation despite the difficult conditions in which they frequently work, show they care for their students and feel they can contribute significantly to their learning. These issues enhance their sense of confidence in their competence and positively influence their resilience.

In turn, Bennett et al. (2013) found that longevity in the field could be explained by children-related, personal, spiritual or family reasons. A complementary point of view in relation to family was offered by Gu and Day (2007) and Meister and Ahrens (2011), who pointed to family support as a key factor that positively influenced VTs' resilience.

Other studies emphasised the negative impact of certain personal issues in the way long-serving teachers serve their profession. For instance, among the VTs portrayed, adverse personal life events or ill health certainly supposed a challenge to sustain their motivation (Day \& Gu, 2009) and certain personal problems were a source of dissatisfaction for them (Veldman et al., 2013). However, Gu and Day (2007) described the case of a female VT who, despite experiencing personal problems, managed to keep high levels of motivation and commitment in her job thanks to the influence of professional and situated issues.

\section{The situated scenario}

School was a space to which most of the teachers interviewed felt they belonged and that transformed their evolving identity. The school was understood as a physical and emotional space that includes relational attributes that flow 'beyond the confines of the school structure and the school day' (McIntyre, 2010, p. 608). Accordingly, McIntyre (2010) referred to the blurring of the boundaries between home and school life, understanding school not only in a physical form, but also from the point of view of the people who live in it. The people with whom teachers related in this space, especially colleagues, administrative staff and 
students, positively or negatively, influenced their identity and also had an impact beyond what was strictly contained within the situated scenario.

The teachers interviewed by McIntyre (2010) described the staff room as a place where they could find friends and colleagues in a supportive environment, a space that mirrored the team spirit of the community. Also Brunetti (2006), Eilam (2009), Gu and Day (2007) and Meister and Ahrens (2011) portrayed colleagues as an important support group with whom teachers interacted or worked in teams and that had a positive impact on their sense of efficacy, their professional growth and/or their resilience in the presence of the challenges in their working environment. On the other hand, an important number of papers highlighted the key role of the leadership exercised by administrators or head teachers in motivating teachers (Bennett et al., 2013; Brunetti, 2006; Day \& Gu, 2009; Gu \& Day, 2007; Levine, 2011; Meister \& Ahrens, 2011; Thorburn, 2014). The resources provided by the administrative office for the teaching in a certain area were also perceived as an indicator of the support and recognition of the administration towards the teachers in that area (Eilam, 2009). From a different but complementary viewpoint, Van Maele and Van Houtte (2012) found that there exist positive relationships between teacher trust in students, parents, colleagues and the principal and job satisfaction, although they stated that the association is slightly stronger when dealing with teacher trust in colleagues and the principal.

The bond teachers established with students was another key factor to explain the commitment, satisfaction and motivation with which the VTs performed at school (Bennett et al., 2013; Day \& Gu, 2009; Gu \& Day, 2007). A good teacher-student relationship, accountability for students' learning, students' affirmation or students' trust were some aspects mentioned as positively contributing to this (Day \& Gu, 2009; Eilam, 2009; Gu \& Day, 2007; Meister \& Ahrens, 2011; Veldman et al., 2013).

Moreover, in relation to students, problematic relationships, deteriorating behaviour and problematic classroom management (Day \& Gu, 2009; Veldman et al., 2013) represented some of the greatest challenges in sustaining teacher motivation. Nevertheless, some papers evidenced that with experience the problems deriving from classroom management tend to decrease (Claessens et al., 2016), which Veldman et al. (2013) associated with a higher level of control and affiliation in regard to students by VTs.

\section{The professional scenario}

The influence of successive political reforms focused on accountability for student achievement was one of the professional factors that showed a greater impact on teacher identity. McIntyre (2010), for example, reported that the culture of accountability exerted a negative impact both in the staffroom and in the classroom, places that had proved to be the locus of teacher identity formation. The culture of accountability forced teachers to change the way they acted at school and added more pressure on their professional work (Day \& Gu, 2009; Gu \& Day, 2007; McIntyre, 2010; Orlando, 2014; Thorburn, 2014). As a result, teachers' professional autonomy decreased (Day \& Gu, 2009) and teachers' satisfaction at work was undermined (Veldman et al., 2013). These situations impacted particularly VTs, who had been able to work with a passion and aplomb difficult to develop under current circumstances in which the technical aspects of teaching are prioritised over the emotional ones (Santoro et al., 2012). The mismatch between teachers' values and those imposed by accountability policies was also evidenced in the case of the VT examined by Thorburn (2014). Whilst excellence standards tend to focus on testing, assessment and examinations, 
these aspects collided with the way he understood excellence based on the development of the student's knowledge, which was intended to influence the student's future life in a positive manner. Other aspects that challenged teacher motivation were related to excessive paperwork, heavy workload, excessively bureaucratic results-driven systems or the need to be up to date in the presence of an avalanche of new initiatives (Bennett et al., 2013; Day \& Gu, 2009; Gu \& Day, 2007).

With regard to this last aspect, Orlando (2014) examined the causes of VTs' lack of motivation toward integrating new technological resources at school. Orlando also found that face with the need to deal with these changes they developed feelings of insecurity, tiredness and scepticism.

Especially vulnerable in the presence of the profession's challenges were VTs who worked in disadvantage communities, on which some of the studies analysed were focused (Brunetti, 2006; Cohen, 2009; McIntyre, 2010; Thorburn, 2014). Despite the difficulties, most of the teachers managed to persist in their field as a result of their sense of efficacy (Gu \& Day, 2007; Meister \& Ahrens, 2011; Thorburn, 2014) and of the positive influence of issues of a different nature. VTs' engagement in certain programmes or activities for professional development was particularly helpful in enhancing their personal evolution and the change in their professional practice (Deglau \& O'Sullivan, 2006; Flint et al., 2011; Levine, 2011; Ponte \& Twomey, 2014).

\section{Discussion and conclusion}

This study has provided an overview of the literature on VTs' identity and has analysed the issues in relation to the teachers' personal, situated and professional scenarios influencing their identity. Figure 1 synthesises these scenarios and their respective influencing issues. Next, the results that are considered most relevant for the purpose of this review are discussed.

Most of the papers analysed delve into the various aspects that facilitate going deeper into the study of identity, although this was not the primary focus. For example, papers that focused on teacher resilience emphasised the issues that motivated teachers to persist in the profession and sustain their commitment. The issues examined connect with teacher identity, which suggests that resilience is closely linked to it. Study of the VTs' identity may, therefore, provide valuable information to contribute to the physical retention of teachers and also influence the issues that have an impact on teacher motivation and commitment, which are, in the end, those with the most implications for teacher efficacy and well-being (Gu \& Day, 2007).

This review has pointed out that the inner motivation to teach is one of the cornerstones on which VTs' resilience is built. Although resilience is considered an essential attribute of teachers' identity at any stage of their careers and a key element in teacher motivation and efficacy (Woods \& Jeffrey, 2002), how to develop it throughout the teaching career remains a challenge. This study has provided data which support the idea that, in the case of VTs, the inner motivation to teach can be strengthened if teachers are to gain satisfaction and fulfilment from their work (Day, 2011; Santoro et al., 2012).

In this sense, this review has evidenced that issues associated with the different scenarios that instil positive emotions in VTs are major sources of satisfaction for teachers and the most likely to exert a profound impact on their identity (e.g. teacher-student relationship, 


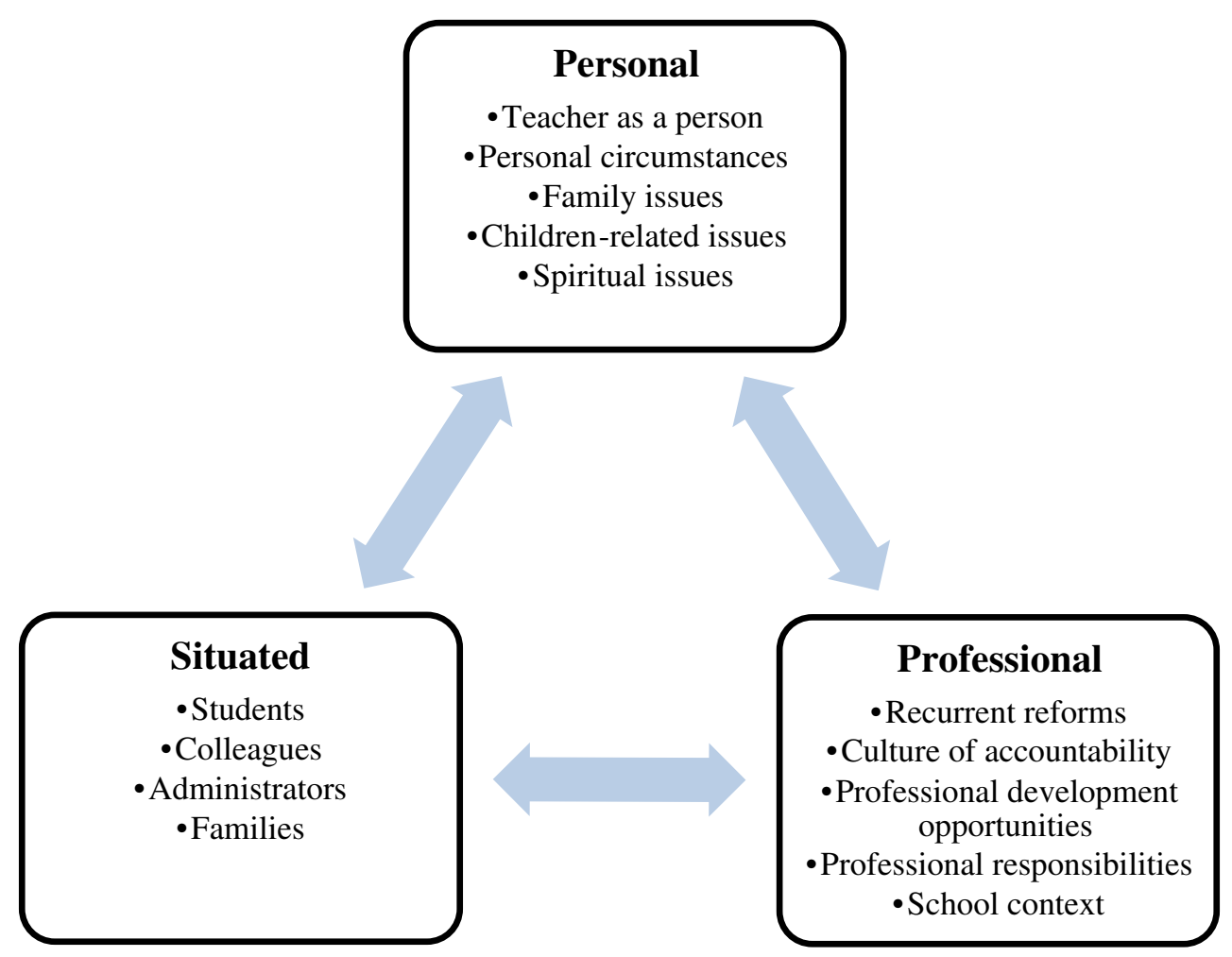

Figure 1. Issues influencing veteran teachers' identity (according to the papers reviewed).

interaction with colleagues and/or the type of leadership by the school administration). In other words, emotions are revealed to be the leitmotif of the transformation of the VTs' identity portrayed in the selected research literature. This perspective would explain why strong support groups at personal and situated levels play a key role in the VTs' motivation and commitment and why political changes disregarding the emotional dimension of the profession frequently manage to destabilise their identity. The latter was also evident with issues such as problematic classroom management, adverse personal factors, excessive paperwork or heavy workload, which triggered feelings of insecurity and vulnerability in the teachers. It therefore seems evident that issues within the three scenarios acknowledging the emotional nature of the profession (Hargreaves, 1998; Nias, 1996) and instilling positive emotions in VTs are likely to contribute to their resilience, ensuring that they will remain in the profession giving the best of themselves in their classrooms.

It is important to highlight that the literature analysed portrayed the VT as a professional with a high degree of confidence in his/her teaching skills (Gu \& Day, 2007; Meister \& Ahrens, 2011; Thorburn, 2014), who managed to find support in issues at the three levels to sustain his/her motivation and commitment. This connects to research carried out within the VITAE project by Day, Stobart, et al. (2006) in which three different scenarios were identified, from the most to the least stable, depicting the fluctuations that teachers experience in relation to each level, and offering a conceptual framework to understand the issues that influence teacher resilience and efficacy. In this section, some issues contributing to teacher motivation and commitment have already been described. However, the findings presented 
in this review have also suggested that specific programmes for professional development may become important resources to support the inner motivation to teach over time.

The emotional nature of the issues associated with motivation and commitment among VTs has implications for school leadership and teacher professional development and policy. First, from a situated perspective, this review has shown that school leadership may impact on VTs' identity in different ways. From the analysis provided in this study it may be inferred that leadership might create a safe and supportive school environment in which teachers can build healthy relationships with students, families and other colleagues. Second, from a professional perspective, this review suggests that educational policy reforms based on accountability are the main source of tension in VTs' identity and the one with the worst consequences for their motivation and commitment. In this sense, this study corroborates earlier studies on the need for policy initiatives to acknowledge and provide teachers with more autonomy in their classroom practices. Teachers' identities are rich and complex and need to be nurtured and developed in trustworthy conditions (Sachs, 2001). From a professional scenario standpoint, relevant professional development opportunities may contribute to this issue.

The role of emotions as a transversal element through the personal, situated and professional scenarios may also help to understand the permeable boundaries of the settings where teachers live and work. McIntyre (2010) referred to the blurring of emotional and physical boundaries between the personal (home) and situated (school) levels. However, permeable boundaries have also become evident between the professional and the situated scenarios (e.g. a culture of accountability having an impact on both the staffroom and the classroom). Therefore this review extends the vision by McIntyre (2010) and suggests that the issues discussed in relation to each scenario are aspects among which there is an interaction and that, despite being different in nature (personal, situated and professional), their influences transcend the boundaries of the scenarios to which they belong. However, further research is needed to gain knowledge on questions such as what we can learn about the degree of intersectionality among the different scenarios. More focus on this issue would contribute to learning more about how teachers manage to stabilise their identities in the presence of adverse influences in given kinds of contexts and it would also allow delving into the role that personal, situated and professional scenarios (and the respective influencing issues) play in the VT's identity structure. For a more complete and thorough view on this topic, future studies should include a focus on the subject taught, since this is one of the pillars on which teacher identity is supported (Carrillo \& Baguley, 2011).

Due to the limited number of papers analysed in this study, future research would also benefit from a wider search through a systematic review of the literature on VTs' identity. This may also include studies on related constructs such as VTs' resilience, which has been shown to have a clear connection with the topic of this research and may provide a more comprehensive view on the literature in this field. In future studies, it would also be interesting to focus on samples of committed VTs in order to provide insights into how these teachers are able to sustain motivation and commitment over time and generate knowledge to support longer and more successful teaching careers in the school setting.

In a time of turmoil for the teaching profession, the wisdom and expertise that VTs can provide to the field should not be dismissed (Hargreaves, 2005). The retention of good-quality teachers is essential to improving school performance (Ingersoll, 2001; Santoro et al., 2012) and those VTs who have managed to overcome the challenges at the personal, 
situational and professional levels and have resiliently remained in the profession doing their best in their classrooms have much to contribute to it. It is therefore important to further examine their legacy. However, there is still much to know and learn from the careers of VTs; not only in terms of what they are and what they do, but also what they think and feel and how they can contribute to the retention and quality teaching of those who enter the profession. The legacy of VTs may be an added source of knowledge to improve the teaching profession and to better handle issues such as teacher attrition and early career teachers' development.

\section{Note}

1. In order to facilitate the reading of this paper, we will refer to these terms as 'issues'.

\section{Disclosure statement}

No potential conflict of interest was reported by the authors.

\section{ORCID}

Carmen Carrillo (D) http://orcid.org/0000-0001-7592-8557

Maria Assunção Flores (iD http://orcid.org/0000-0002-4698-7483

\section{References}

Alger, C. L. (2009). Secondary teachers' conceptual metaphors of teaching and learning: Changes over the career span. Teaching and Teacher Education, 25, 743-751.

Antonek, J. L., McCormick, D. E., \& Donato, R. (1997). The student teacher portfolio as autobiography: Developing a professional identity. Modern Language Journal, 81(1), 15-27.

Beauchamp, C., \& Thomas, L. (2009). Understanding teacher identity: An overview of issues in the literature and implications for teacher education. Cambridge Journal of Education, 39, 175-189.

Beijaard, D., Verloop, N., \& Vermunt, J. (1999). Teachers' perceptions of professional identity: An exploratory study from a personal knowledge perspective. Teaching and Teacher Education, 16, 749-764.

Beijaard, D., Meijer, P.C., \& Verloop, N. (2004). Reconsidering research on teachers' professional identity. Teaching and Teacher Education, 20, 107-128.

Beltman, S., Mansfield, C., \& Price, A. (2011). Thriving not just surviving: A review of research on teacher resilience. Educational Research Review, 6(3), 185-207.

Bennett, S. V., Brown, J.J., Kirby-Smith, A., \& Severson, B. (2013). Influences of the heart: Novice and experienced teachers remaining in the field. Teacher Development, 17, 562-576.

Brunetti, G. (2006). Resilience under fire: Perspectives on the work of experienced, inner city high school teachers in the United States. Teaching and Teacher Education, 22, 812-825.

Bryman, A. (2012). Social Research Methods (4th ed.). Oxford: Oxford University Press.

Carrillo, C., \& Baguley, M. (2011). From school teacher to university lecturer: Illuminating the journey from the classroom to the university for two arts educators. Teaching and Teacher Education, 27, $62-72$.

Claessens, L., van Tartwijk, J., Pennings, H., van der Want, A., Verloop, N., den Brok, P., \& Wubbels, T. (2016). Beginning and experienced secondary school teachers' self- and student schema in positive and problematic teacher-student relationships. Teaching and Teacher Education, 55, 88-99.

Cohen, R.M. (2009). What it takes to stick it out: Two veteran inner-city teachers after 25 years. Teachers and Teaching: Theory and Practice, 15, 471-491. 
Conway, P. (2001). Anticipatory reflection while learning to teach: From a temporally truncated to a temporally distributed model of reflection in teacher education. Teaching and Teacher Education, $17,89-106$.

Creswell, J. W. (1997). Qualitative inquiry and research design: Choosing among five traditions. Thousand Oaks, CA: Sage.

Day, C. (2002). School reform and transitions in teacher professionalism and identity. International Journal of Educational Research, 37, 677-692.

Day, C. (2011). Pasión por enseñar. La identidad personal y profesional del docente y sus valores. Madrid: Narcea.

Day, C., \& Gu, Q. (2009). Veteran teachers: Commitment, resilience and quality retention. Teachers and Teaching: Theory and Practice, 15, 441-457.

Day, C., Kington, A., Stobart, G., \& Sammons, P. (2006). The personal and professional selves of teachers: Stable and instable identities. British Educational Research Journal, 32, 601-616.

Day, C., Stobart, G., Sammons, P., Kington, A., Gu, Q., Smees, R., \& Mujtaba, T. (2006). Variations in teachers' work, lives and effectiveness (VITAE). London: Department for Education and Skills.

Deglau, D., \& O'Sullivan, M. (2006). The effects of a long-term professional development program on the beliefs and practice of experienced teachers. Journal of Teaching in Physical Education, 25, 379-396.

Eilam, B. (2009). The secrets of successful veteran biology teachers: Metaphors of evolution, regeneration, and adaptation. Teachers and Teaching: Theory and Practice, 15, 493-513.

Erlandson, D. A., Harris, E. L., Skipper, B. L., \& Allen, S. D. (1993). Doing naturalistic inquiry. A guide to methods. London: Sage.

Flint, A. S., Zisook, K., \& Fisher, T. R. (2011). Not a one-shot deal: Generative professional development among experienced teachers. Teaching and Teacher Education, 27, 1163-1169.

Flores, M.A., \& Day, C. (2006). Contexts which shape and reshape new teachers' identities: A multiperspective study. Teaching and Teacher Education, 22, 219-232.

Goodson, I., Moore, S., \& Hargreaves, A. (2006). Teacher nostalgia and the sustainability of reform: The generation and degenaration of teachers' missions, memory, and meaning. Educational Administration Quarterly, 42, 42-61.

Gu, Q., \& Day, C. (2007). Teacher's resilience: A necessary condition for effectiveness. Teaching and Teacher Education, 23, 1302-1316.

Hargreaves, A. (1998). The emotional practice of teaching. Teaching and Teacher Education, 14, $835-854$.

Hargreaves, A. (2005). Educational change takes ages: Life, career and generational factors in teachers' emotional responses to educational change. Teaching and Teacher Education, 21, 967-983.

Hong, J. Y. (2010). Pre-service and beginning teachers' professional identity and its relation to dropping out of the profession. Teaching and Teacher Education, 26, 1530-1543.

Huberman, M. (1993). The lives of teachers. New York, NY: Teachers College Press.

Huberman, A. B., \& Miles, M. (1994). Data management and analysis methods. In N. K. Denzin \& Y. S. Lincoln (Eds.), Handbook of qualitative research (pp. 228-244). Thousand Oaks, CA: Sage.

Ingersoll, R. M. (2001). Teacher turnover and teacher shortages: An organizational analysis. American Educational Research Journal, 38, 499-534.

Knowles, G. J. (1992). Models for understanding pre-service and beginning teachers' biographies: Illustrations from case studies. In I. F. Goodson (Ed.), Studying teachers' lives (pp. 99-152). London: Routledge.

Levine, T. H. (2011). Experienced teachers and school reform: Exploring how two different professional communities facilitated and complicated change. Improving Schools, 14, 30-47.

Lieberman, A., \& Pointer Mace, D. H. (2009). The role of 'accomplished teachers' in professional learning communities: Uncovering practice and enabling leadership. Teachers and Teaching: Theory and Practice, 15, 459-470.

Lincoln, Y. S., \& Guba, E. G. (1985). Naturalistic Inquiry. Newbury Park, CA: Sage Publications.

MacLure, M. (1993). Arguing for yourself: Identity as an organizing principle in teachers' jobs and lives. British Educational Research Journal, 19, 311-322. 
Margolis, J. (2008). What will keep today's teachers teaching? Looking for a hook as a new career cycle emerges. Teachers College Record, 110, 160-194.

McIntyre, J. (2010). Why they sat still: The ideas and values of long-serving teachers in challenging inner-city schools in England. Teachers and Teaching: Theory and Practice, 16, 595-614.

Meister, D. G., \& Ahrens, P. (2011). Resisting plateauing: Four veteran teachers' stories. Teaching and Teacher Education, 27, 770-778.

Nias, J. (1996). Thinking about feeling: The emotions in teaching. Cambridge Journal of Education, 26, 293-306.

OECD [Organization for Economic Cooperation and Development] (2005). Teachers matter: Attracting, developing and retaining effective teachers. Paris: OECD.

Orlando, J. (2014). Veteran teachers and technology: Change fatigue and knowledge insecurity influence practice. Teachers and Teaching: Theory and Practice, 20, 427-439.

Pillen, M. T., Den Brok, P. J., \& Beijaard, D. (2013). Profiles and change in beginning teachers' professional identity tensions. Teaching and Teacher Education, 34, 86-97.

Ponte, E., \& Twomey, S. (2014). Veteran teachers mentoring in training: Negotiating issues of power, vulnerability and professional development. Journal of Education for Teaching, 40, 20-33.

Roberts, L. (2000). Shifting identities: An investigation into student and novice teachers' evolving professional identity. Journal of Education for Teaching, 26(2), 185-186.

Ryan, G. W., \& Bernard, H. R. (2000). Data management and analysis methods. In N. K. Denzin \& Y. S. Lincoln (Eds.), Handbook of qualitative research (2nd ed.). (pp. 769-802). Thousand Oaks, CA: Sage.

Sachs, J. (2001). Teacher professional identity: Competing discourses, competing outcomes. Journal of Education Policy, 16, 149-161.

Santoro, N., Pietsch, M., \& Borg, T. (2012). The passion of teaching: Learning from an older generation of teachers. Journal of Education for Teaching, 38, 585-595.

Sugrue, C. (1997). Student teachers' lay theories and teaching identities: Their implications for professional development. European Journal of Teacher Education, 20(3), 213-225.

Thorburn, M. (2014). 'It was the best of times, it was the ...': Subject aims and professional identity from the perspective of one veteran male teacher of physical education in Scotland. Teachers and Teaching: Theory and Practice, 20, 440-452.

Van Houtte, M. (2006). Tracking and teacher satisfaction: Role of study culture and trust. Journal of Educational Research, 99, 247-254.

Van Maele, D., \& Van Houtte, M. (2012). The role of teacher and faculty trust in forming teachers' job satisfaction: Do years of experience make a difference? Teaching and Teacher Education, 28, 879-889.

Veldman, I., van Tartwijk, J., Brekelmans, M., \& Wubbels, T. (2013). Job satisfaction and teacherstudent relationships across the teaching career: Four case studies. Teaching and Teacher Education, $32,55-65$.

Volkmann, M. J., \& Anderson, M. A. (1998). Creating professional identity: Dilemmas and metaphors of a first-year chemistry teacher. Science Education, 82(3), 293-310.

Woods, P., \& Jeffrey, B. (2002). The reconstruction of primary teachers' identities. British Journal of Sociology for Education, 23, 89-106. 


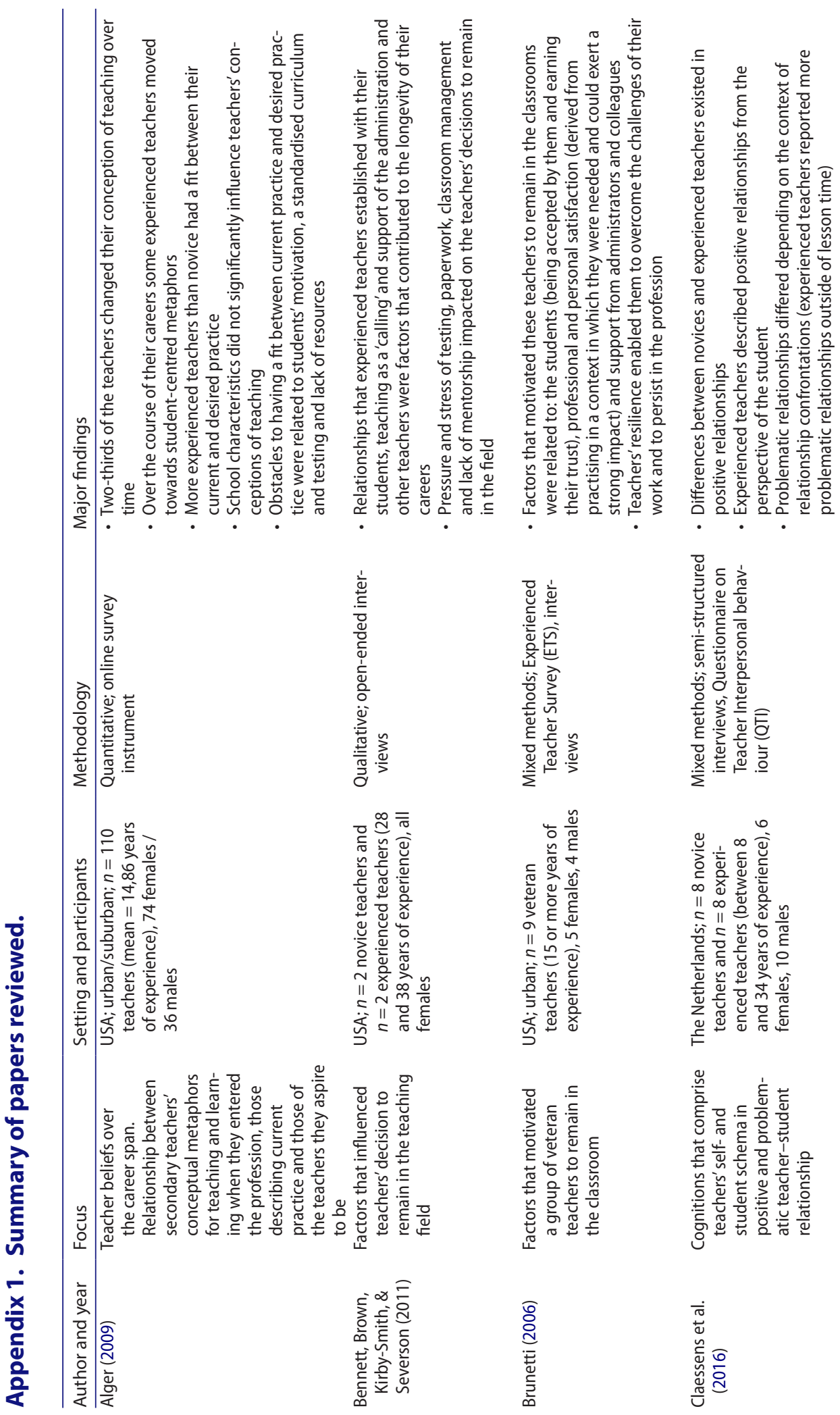



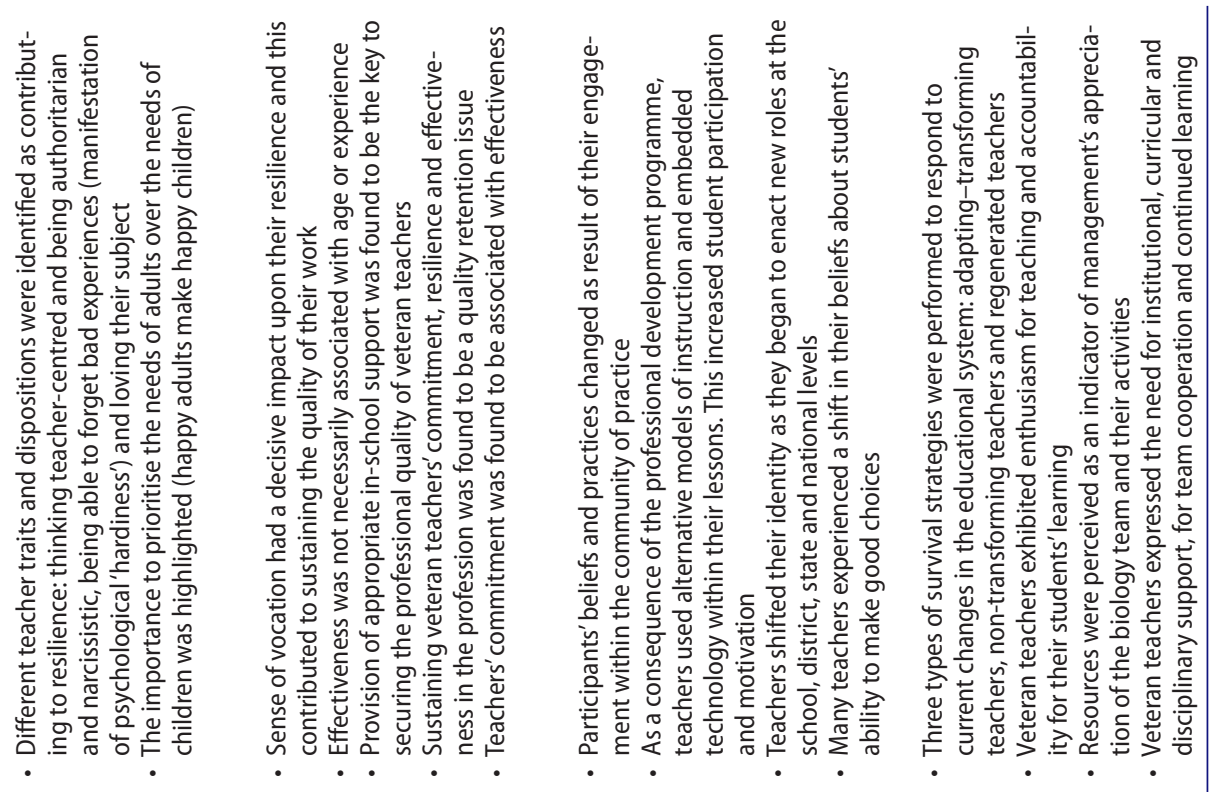

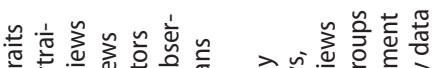

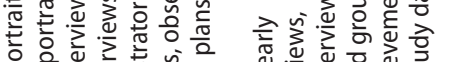

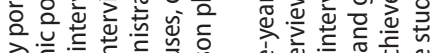

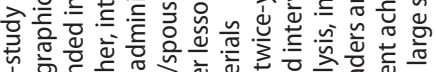

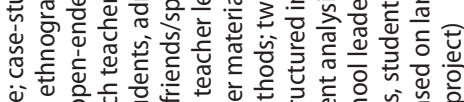

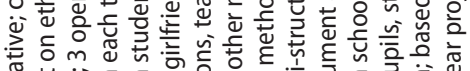

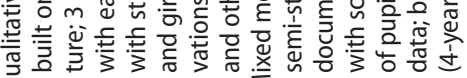

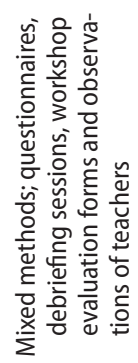

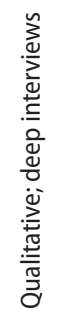
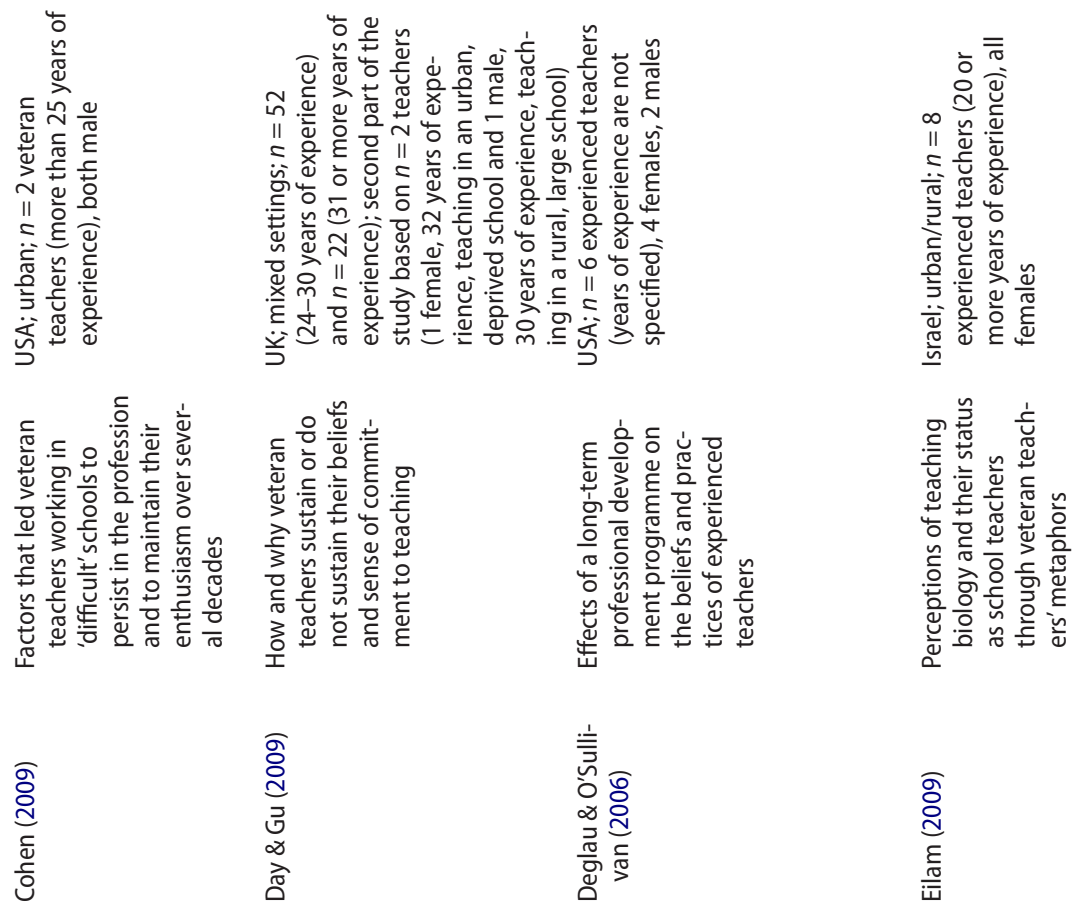

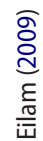

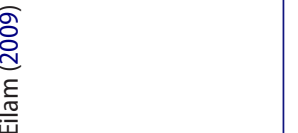




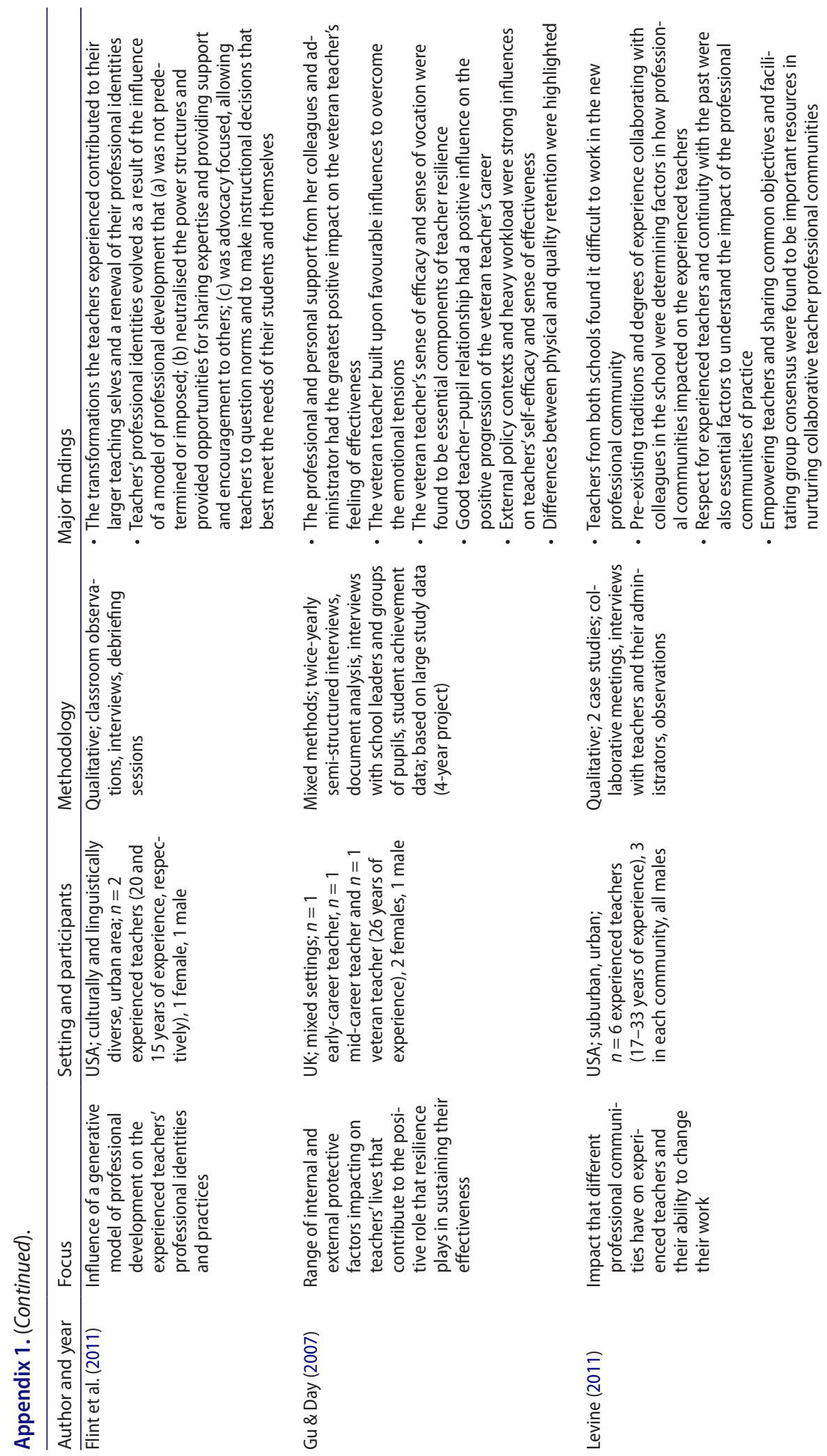



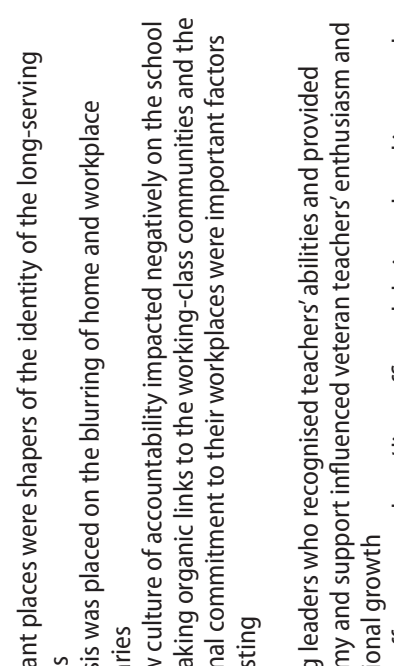

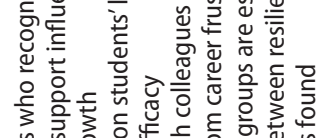

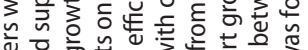

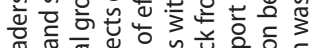

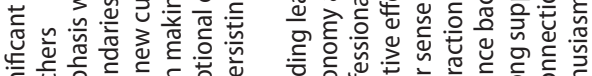

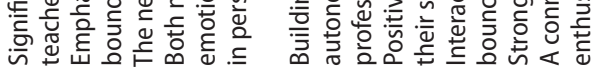
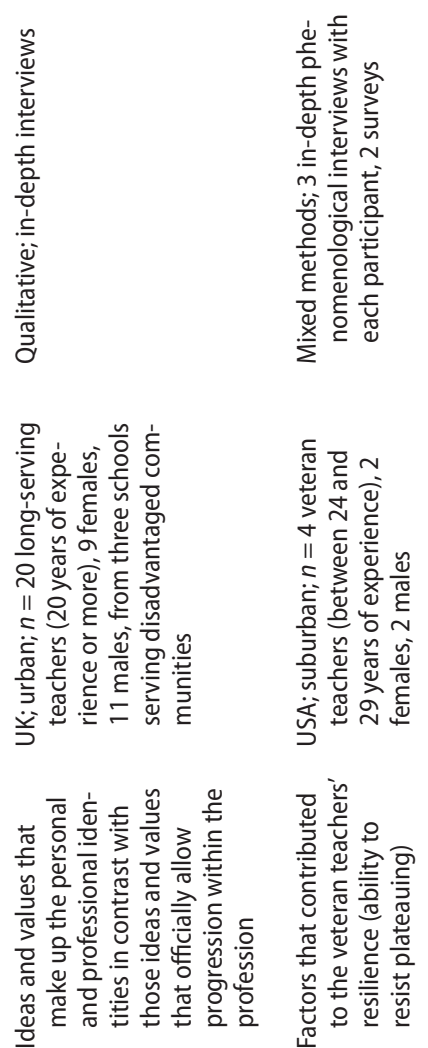

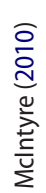

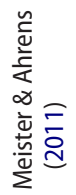

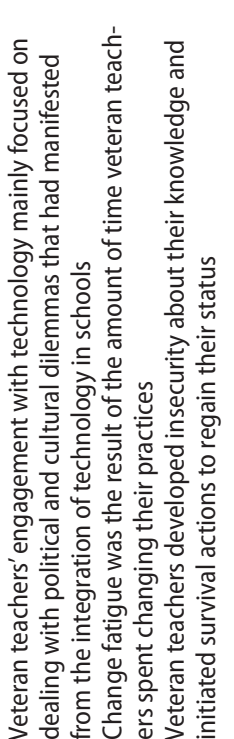

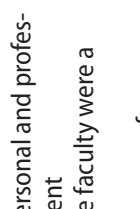

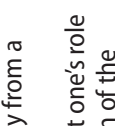
बे 응 谙.

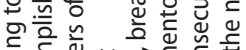

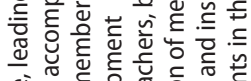
仓ं

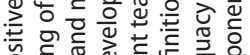

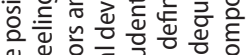

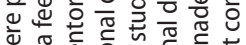
我 凹

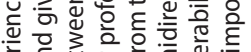

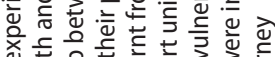

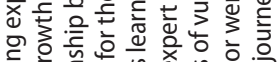

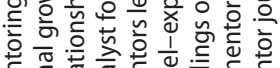

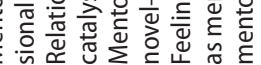

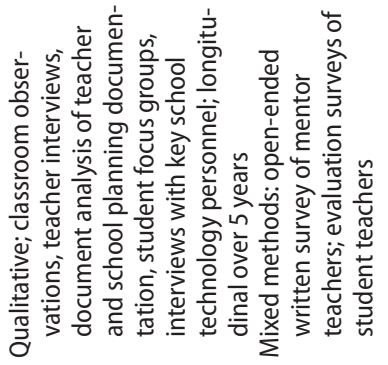

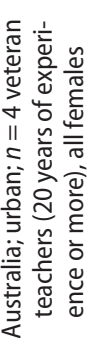
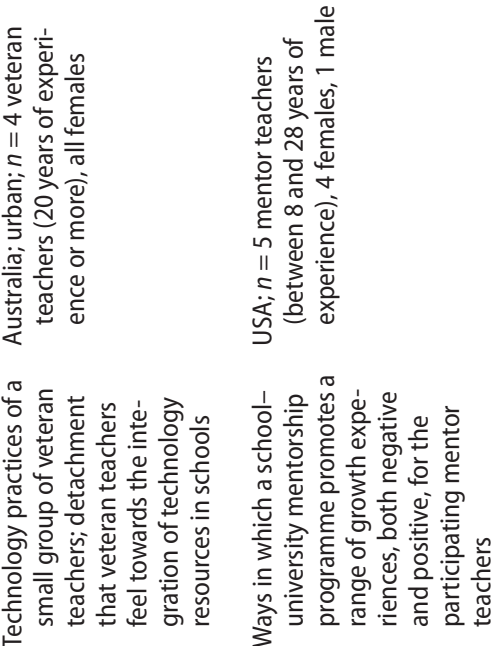

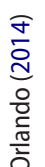

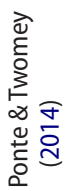




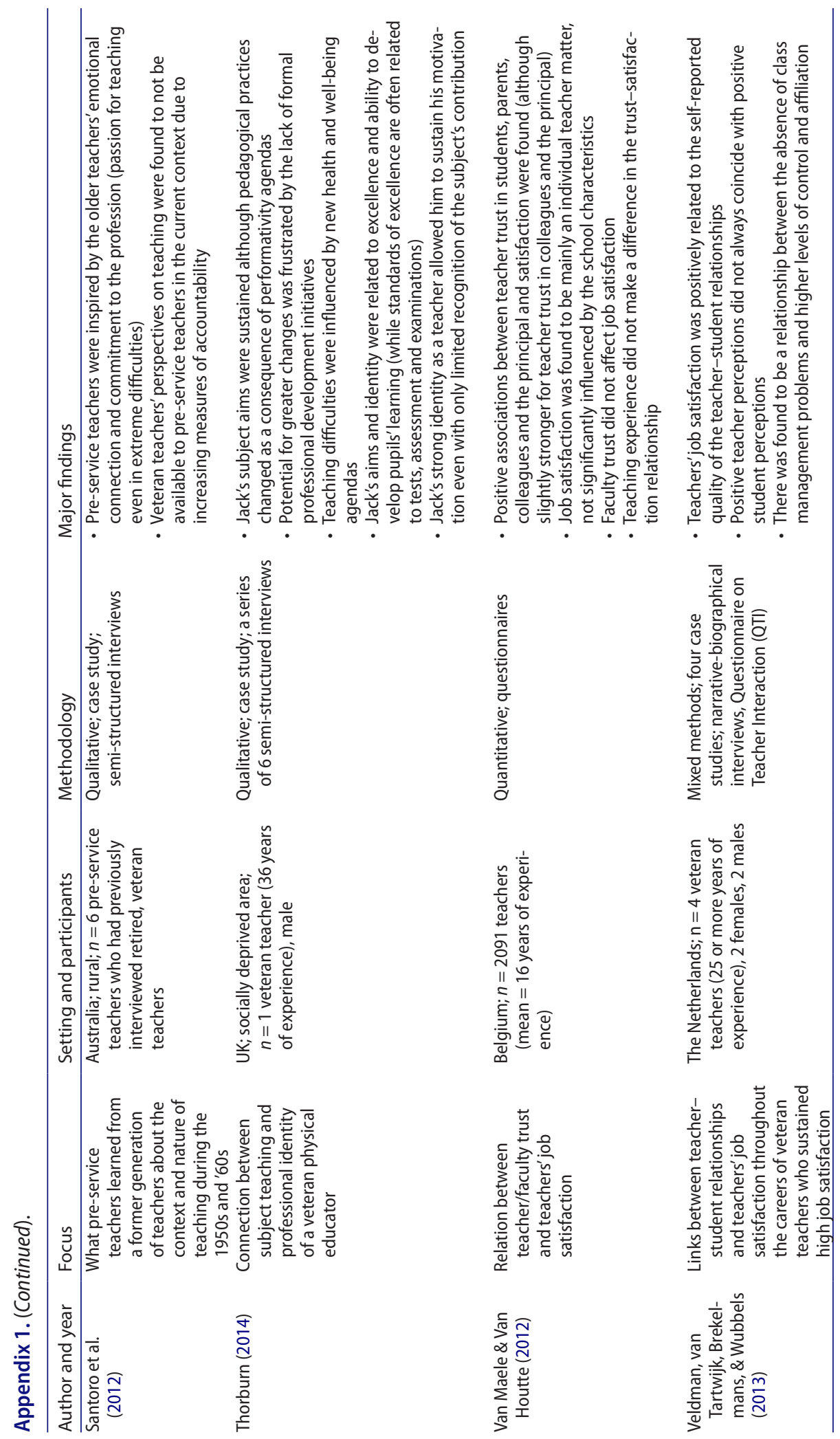

